Australia and Algeria (representing France) in paying for this work; the problems to be solved are mainly those of bringing up the process from small to large pilot-plant scale. In Britain, an Admiralty team has been working on scale- and foam-prevention in the distillation of sea-water. The Department of Scientific and Industrial Research has now given $£ 5,000$ for an extension of that programme to cover other waters. A Dutch scientist is joining the team. Two other processes have been put forward by the French, namely, certain aspects of ion-exchange and of solar distillation, which may be suitable for use in very hot, dry areas; no co-operative group for their study has yet been formed.

\section{New Discovery at Swanscombe, Kent}

Some time must necessarily elapse before a complete study can be made of the portion of a human skull bone discovered at Swanscombe by Mr. and Mrs. B. O. Wymer, Mr. J. Wymer, and Mr. Adrian Jones on August 1. It can, however, be confirmed that the bone is a right parietal, and it fits perfectly with the left parietal and occipital which were discovered on the same site by Mr. A. T. Marston in January 1935. This in itself is very satisfactory, and will enable further evidence to be obtained from the bones as a whole. Meanwhile, the remarkable fact that another portion of the same skull has been found after an interval of twenty years is a striking justification of the policy of the Nature Conservancy in preserving sites of scientific importance. The remaining region of the Swanscombe skull has still to be discovered, and it is very much to be hoped that it will be found during the further excavations which it is understood are to be made. It is therefore of the greatest importance that the site should be protected from damage.

\section{Commonwealth Agricultural Bureaux}

THE growth of the Commonwealth Agricultural Bureaux, like so many other British organizations, has been one of adaptation and adjustment, often on an empirical basis, to the needs and mood of the time. It dates back to 1909 , when recommendations were made for forming an Entomological Research Committee, duly leading in 1913 to the foundation of the Imperial Bureau of Entomology, and to 1920, when an Imperial Bureau of Mycology was started. In addition to these two bodies, now named the Commonwealth Institute of Entomology and the Commonwealth Mycological Institute, respectively, eleven other Commonwealth centres were later founded, as follows : Institute of Biological Control, Bureau of Agricultural Parasitology, Bureau of Animal Breeding and Genetics, Bureau of Animal Health, Bureau of Animal Nutrition, Bureau of Dairy Science, Bureau of Forestry, Bureau of Horticulture and Plantation Crops, Bureau of Pastures and Field Crops, Bureau of Plant Breeding and Genetics, and Bureau of Soil Science. Though these centres are situated in Great Britain, they are essentially Commonwealth organizations and are in the hands of an Executive Council which comprises one member from Great Britain and one from each of the Dominions of the British Commonwealth (including the Republic of India and the Federation of Rhodesia and Nyasaland) and one member representing the Colonial Territories. One of the recommendations of the Commonwealth Agricultural Bureaux Conference of 1946 was that the Executive Council should issue a conspectus showing the subjects or aspects of subjects covered by the journals of the institutes and bureaux. At the same time it was decided to incorporate a brief account of the history and origin of the Commonwealth Agricultural Bureaux organization. As a result, the conspectus was issued in 1949 giving a short description of the history, work, administration and finance of the Bureaux and a detailed review of the subjects covered by each institute and bureau. The conspectus has now been revised and is a valuable pamphlet of nearly fifty pages (London : H.M.S.O., 1955) showing the state of the Commonwealth Agricultural Bureaux at the time of going to press in October last year.

\section{National Institute of Agricultural Botany}

IN his address to the Fellows of the National Institute of Agricultural Botany, Cambridge, at the annual general meeting of the Institute on July 14, Sir William Slater said that a fundamental feature of the Institute's work has been the introduction of greater precision into the evaluation of the different varieties of agricultural and horticultural crops, and as a result the farmer and grower now have information upon which they can rely. With regard to plant breeding, he believes that undue emphasis is sometimes laid on a search for an ideal variety incorporating all possible good qualities, whereas a sound range of good varieties of known performance, from which the farmer can select according to his requirements, may be preferable. Prof. T. J. Jenkin, chairman of the Council, in presenting the annual report for 1954, referred to the arrangements for transfer from the Welsh Plant Breeding Station of the certification of the Aberystwyth strains of grasses and clovers, and for sowing an additional acreage of foundation seed as the first stage towards full responsibility by the National Institute of Agricultural Botany for the production of stock seed of these strains. A recommended list for the potato crop has been produced for the first time, the certification schemes for cereals have been developed and a new scheme inaugurated for vegetables. Considerable progress has also been made in the national certification scheme for herbage plants. In conclusion, he was able to announce the authorization by the Ministry and Treasury of a capital grant for a much-needed extension to the headquarters building and for improvements in glasshouse accommodation.

\section{Institute of Science Technology}

IN 1948, the Science Technologists Association was formed for technicians in science laboratories in educational institutions and in industry who were not covered by the Institute of Medical Laboratory Technology. The membership has now grown to approximately 1,300, and many branches have been formed providing for local activities. The Education Board of the Association has arranged examinations at both certificate and diploma level, and the Association has assisted in the training of technicians in other ways and has maintained a technical information service. A primary purpose of the Association had always been the formation of an Institute of Science Technology, and this was accomplished at an extraordinary general meeting of the Association held on May 21. The Institute has been granted a certificate of incorporation and has taken over the affairs of the Association. Membership of the Institute will consist of Fellows, honorary Fellows, associates, ordinary members and registered students; the training scheme approved by the Institute is a 